\title{
Effect of intrauterine dextrose on reproductive performance of lactating dairy cows diagnosed with purulent vaginal discharge under certified organic management
}

\author{
M. G. Maquivar, ${ }^{* 1}$ A. A. Barragan, ${ }^{*}$ J. S. Velez, $†$ H. Bothe, $†$ and G. M. Schuenemann*2 \\ ${ }^{*}$ Department of Veterinary Preventive Medicine, College of Veterinary Medicine, The Ohio State University, Columbus 43210 \\ †Aurora Organic Farms, Boulder, CO 80302
}

\begin{abstract}
The objectives of the study were to assess responses to treatments (clinical cure and resumption of estrous cycles) of cows with purulent vaginal discharge (PVD) that received intrauterine infusion of a hypertonic solution of $50 \%$ dextrose (DEX) or untreated control (CON) cows and the subsequent pregnancy per artificial insemination (PAI) in cows with and without PVD. Cows $(\mathrm{n}=2,852)$ from 2 dairy herds were screened for PVD using the gloved hand technique at exam $1[26 \pm 3 \mathrm{~d}$ in milk (DIM)]. Cows with vaginal discharge scores of 2 or $3(0-3$ scale) were stratified by parity and randomly allocated into 1 of 2 treatment groups: (1) intrauterine infusion $(\sim 200 \mathrm{~mL})$ of $50 \%$ DEX solution $(\mathrm{n}=456)$, or (2) untreated control animals $(\mathrm{CON}, \mathrm{n}=491)$. Fourteen days posttherapy (40 \pm 3 DIM), cows with PVD were re-examined at exam $2(40 \pm 3 \mathrm{DIM})$ to assess the response to treatments. All cows were subjected to the same reproductive program, which consisted of estrus detection twice daily (using tail chalking and visual observation) for the first 5 artificial inseminations; then, open lactating cows were turned out with bulls. Cows displaying signs of standing estrus underwent AI and no reproductive hormones were used. Pregnancy diagnosis $(\mathrm{PD})$ was performed via transrectal palpation at $40 \pm 3 \mathrm{~d}$ post-AI. The risk of culling within $14 \mathrm{~d}$ posttherapy was not different among treatment groups. Cows with PVD had greater cervical diameter at exam 1 and decreased PAI compared with cows without PVD. Treatment with DEX increased the proportion of cows with clear vaginal discharge (clinical cure) and cyclicity $14 \mathrm{~d}$ posttherapy compared with CON cows. Pregnancy per AI for DEX (29.2 $\pm 2 \%)$ cows was significantly greater than that for $\mathrm{CON}(22.5 \pm 2 \%)$ cows.

\footnotetext{
Received November 6, 2014.

Accepted February 10, 2015.

${ }^{1}$ Current address: Department of Animal Sciences, Washington

${ }^{2}$ Corresponding author: schuenemann.5@osu.edu
} State University, Pullman, WA 99164.
\end{abstract}

Cows without PVD had a greater proportion of cycling cows $(65.6 \%)$ and PAI $(37 \%)$ with reduced pregnancy losses $(5.7 \%)$ compared with DEX or CON cows. The use of intrauterine DEX alone improved reproductive performance of cows with PVD.

Key words: clinical endometritis, reproductive performance, organic dairy

\section{INTRODUCTION}

Postpartum uterine diseases such as metritis and clinical endometritis (CE) are common disorders of lactating dairy cows that negatively affect reproductive performance (LeBlanc et al., 2002a; Gilbert et al., 2005; Brick et al., 2012) and thus diminish the profitability of dairy operations (Overton and Fetrow, 2008). Clinical endometritis is defined as the inflammation of the endometrial lining of the uterus characterized clinically by mucopurulent or purulent vaginal discharge (PVD), or characterized cytologically by endometrial inflammation occurring 21 to 40 DIM (LeBlanc et al., 2002a; Gilbert et al., 2005; Dubuc et al., 2011a). Risk factors such as hygiene of the perineum at the time of calving (Schuenemann et al., 2011), peripartum metabolic status (Földi et al., 2006; LeBlanc, 2008), parity (Dubuc et al., 2011b), retained fetal membranes (LeBlanc et al., 2002a; Sheldon et al., 2009), delivery of twins (Földi et al., 2006), and dystocia (Földi et al., 2006) have all been associated with $\mathrm{CE}$ in lactating dairy cows. Moreover, $\mathrm{CE}$ has been shown to contribute to ovarian dysfunction (e.g., smaller follicle size, lower plasma estradiol concentration, and prolonged luteal phase; Sheldon et al., 2009), poor reproductive performance (LeBlanc et al., 2002a; Brick et al., 2012), increased risk of culling due to reproductive failure (LeBlanc et al., 2002a,b), and reduced milk yield (Dubuc et al., 2011b).

Although administration of $\mathrm{PGF}_{2 \alpha}$ (Heuwieser et al., 2000; Kasimanickam et al., 2005; Dubuc et al., 2011a) is often recommended to treat $\mathrm{CE}$, conflicting data exist in the literature regarding the potential reproductive benefits. Antibiotic therapy, such as treatment with 
cephapirin, is frequently prescribed to treat cows with CE (LeBlanc et al., 2002b) or vulvar discharges $>13 \mathrm{~d}$ postpartum (McDougall, 2001) in dairy herds. Ceftiofur sodium (Drillich et al., 2001), ceftiofur hydrochloride (Kasimanickam et al., 2010), and ceftiofur crystalline free acid (McLaughlin et al., 2010) have been shown to be effective (resulting in clinical recovery) for treatment of metritis. However, no antimicrobial is approved in the United States for treatment of CE or PVD in dairy cattle.

An in vitro study showed that mannose (a sugar monomer) inhibits the adhesion of bacteria such as Escherichia coli to cultured equine endometrial epithelial cells (King et al., 2000). In addition, the use of hypertonic sucrose solutions inhibits bacterial growth such as E. coli from infected human wounds (Chirife et al., 1983). The emergence of multidrug resistance in Arcanobacterium pyogenes (reclassified as Trueperella pyogenes) and E. coli, important pathogens associated with uterine infections (Sheldon and Dobson, 2004; Williams et al., 2005), has been reported in dairy cows suffering from metritis (Santos et al., 2010). A recent study showed that the use of a hypertonic solution (e.g., $50 \%$ dextrose in water) improves clinical cure of lactating dairy cows with CE compared with untreated control cows under conventional management (Brick et al., 2012).

The first objective of this study was to determine the effect of PVD on reproductive performance of lactating dairy cows under certified organic management. The hypothesis was that PVD would be detrimental to pregnancies per AI (PAI) compared with cows without PVD. The second objective was to compare the response to treatments (clinical cure and resumption of the postpartum estrous cycles $14 \mathrm{~d}$ posttherapy) in lactating dairy cows diagnosed with PVD and treated with an intrauterine infusion of a hypertonic solution of $50 \%$ dextrose (DEX) compared with untreated control (CON) cows. The hypothesis was that the administration of intrauterine DEX infusion would improve clinical cure and resumption of the postpartum estrous cycles in lactating dairy cows with PVD. The third objective was to determine the effect of intrauterine DEX in cows with PVD on PAI compared with CON cows or cows without PVD. The hypothesis was that PVD would be detrimental to PAI but that treatment with DEX would improve PAI in lactating dairy cows.

\section{MATERIALS AND METHODS}

\section{Facilities, Animals, and Feeding Management}

A total of 3,181 lactating dairy cows (1,544 primiparous and 1,637 multiparous) from 2 certified organic dairy farms in Colorado were used in the present study. The breed distribution was Holstein $(\mathrm{n}=2,493)$, Jersey $(\mathrm{n}=61)$, and Holstein $\times$ Jersey cross $(\mathrm{n}=298)$. Briefly, cows were housed in freestall barns with open access to a contiguous dry lot. All cows were milked thrice daily at approximately 8-h intervals, and the rolling herd average milk production was $8,800 \mathrm{~kg}$ with a reported voluntary waiting period of $45 \mathrm{~d}$. From May to September, all cows had access to pasture (mixture of alfalfa, ryegrass, and orchardgrass, as well as triticale, wheat, and sorghum). Additionally, cows were fed twice daily, in the morning and afternoon, with a TMR formulated to meet or exceed dietary nutritional requirements for lactating dairy cows (NRC, 2001). This study was conducted from January through December 2012. The procedures described below were reviewed by The Ohio State University Institutional Animal Care and Use Committee.

\section{Diagnosis of PVD, Ovarian Structures, and Treatments}

Weekly, a list of cows was obtained based on their calving dates using on-farm computer records (PCDART, Dairy Record Management Systems, Raleigh, NC). Briefly, cows at $26 \pm 3$ DIM were restrained using headlocks within the pen immediately after milking for the diagnosis of PVD using the gloved hand technique (Williams et al., 2005), measurement of cervix diameters, and recording of ovarian structures by ultrasonography (Brick et al., 2012). Once the cow was in the headlock, the uterus was massaged via transrectal palpation, the perineal area was cleaned, and vulva was wiped off with paper towel. Then, a lubricated gloved hand was introduced through the vulva to the vaginal vault and cervical os, and the vaginal content was withdrawn manually for assessment at first gynecological examination (exam 1; Figure 1). The vaginal discharge was scored using a $0-3$ scale $(0=$ normal uterine discharge, $1=$ flakes of purulent exudates in the uterine discharge, $2=>50 \%$ of the uterine discharge is made up of purulent exudates, $3=$ hemorrhagic uterine discharge mixed with purulent exudates; adapted from Williams et al., 2005; Sheldon et al., 2006). Purulent vaginal discharge was defined as a score of 2 or 3 (mucopurulent or worse vaginal discharge) at the time of exam 1. Cervix diameters at exam $1(26 \pm 3$ DIM) were classified as $<3.0$ or $>3.1 \mathrm{~cm}$ (Table 1 ).

Immediately before the PVD examination, rectal temperatures (ReliOn, Waukegan, IL) were recorded. The presence or absence of ovarian structures, such as corpus luteum $(\mathbf{C L})$, follicles $(>3 \mathrm{~mm})$, or cysts, was recorded via transrectal ultrasonography (Easi-Scan, BCF Technology, Rochester, MN) at exam 1 and at the 


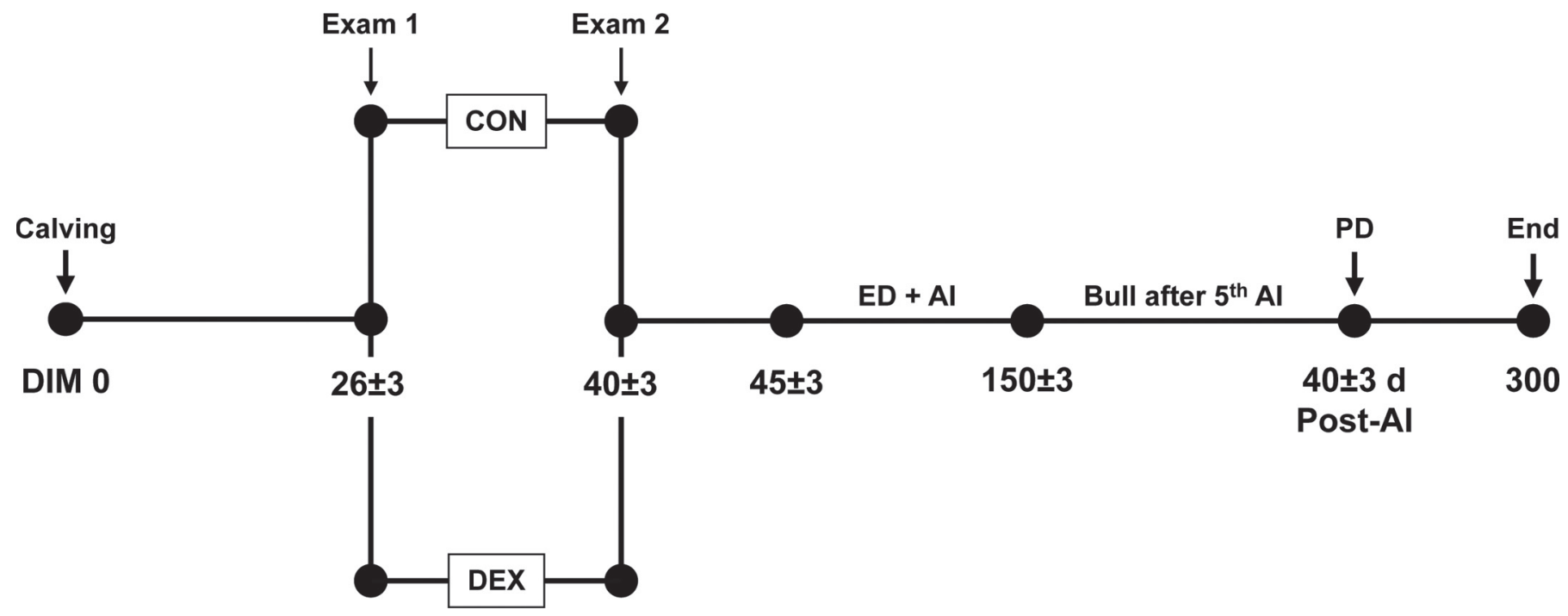

Figure 1. Scheme of the experimental design. Lactating dairy cows $(n=2,852)$ were screened for purulent vaginal discharge (PVD) at 26 \pm 3 DIM using the gloved hand technique (exam 1). Cows diagnosed with PVD (score 2 or 3 ) were randomly assigned into 1 of 2 groups: (1) intrauterine infusion $(\sim 200 \mathrm{~mL})$ of a $50 \%$ dextrose solution $(\mathrm{DEX} ; \mathrm{n}=456)$, or $(2)$ untreated control cows $($ CON; $\mathrm{n}=491)$. Cows with PVD were subjected to a second gynecological exam (exam 2) $14 \mathrm{~d}$ later to assess the response to treatments (clinical cure). All cows (with and without PVD) were subjected to the same reproductive program (estrus detection; ED) plus AI for the first 5 inseminations; then, cows were turned out with bulls. Pregnancy diagnosis (PD) was performed via transrectal ultrasonography at $40 \pm 3 \mathrm{~d}$ post-AI.

second gynecological examination (exam 2; Figure 1). Cysts were defined as follicle-like structures $>25 \mathrm{~mm}$ in diameter (Stevenson and Tiffany, 2004), regardless of the presence or absence of a CL. Additionally, cows had their BCS (scale 0-5; Ferguson et al., 1994) recorded at calving and at $26 \pm 3$ DIM (Figure 1).
Cows with PVD (uterine discharge scores of 2 or 3 ) were stratified by parity and randomly allocated into 1 of 2 treatment groups: (1) intrauterine infusion $(\sim 200$ $\mathrm{mL}$ ) of a $50 \%$ dextrose solution (DEX; $\mathrm{n}=456$; Vedco, Saint Joseph, MO), or (2) untreated control cows (CON; $\mathrm{n}=491$; no placebo was used). The intrauterine

Table 1. Prevalence (\%) of purulent vaginal discharge (PVD) at exam 1 (26 \pm 3 DIM) and at exam $2(40 \pm$ 3 DIM) of lactating Holstein cows $(\mathrm{n}=2,852)$ using the gloved hand scoring technique and measurement of cervical diameter by ultrasonography

\begin{tabular}{|c|c|c|c|c|}
\hline \multirow[b]{2}{*}{ Parameter } & \multirow[b]{2}{*}{ Exam $1^{1}$} & \multicolumn{2}{|c|}{ Exam $2^{2}$} & \multirow[b]{2}{*}{$P$-value } \\
\hline & & $\begin{array}{c}\text { CON } \\
(\mathrm{n}=491)\end{array}$ & $\begin{array}{c}\text { DEX } \\
(\mathrm{n}=456)\end{array}$ & \\
\hline \multicolumn{5}{|l|}{ Clinical vaginal discharge } \\
\hline 0 (clear mucus) & $42.6(\mathrm{n}=1,214)$ & $51.1^{\mathrm{b}}$ & $59.7^{\mathrm{a}}$ & 0.04 \\
\hline 1 (mucus with flecks of pus) & $24.2(\mathrm{n}=689)$ & & & \\
\hline 2 (mucopurulent) & $24.9(\mathrm{n}=711)$ & 42.7 & 34.5 & \\
\hline 3 (brown-red foul) & $8.3(\mathrm{n}=238)$ & 6.2 & 5.8 & \\
\hline \multicolumn{5}{|l|}{ Cervical diameter $(\mathrm{cm})$} \\
\hline$\leq 3.0$ & $72(\mathrm{n}=2,053)$ & 86.4 & 84.9 & \\
\hline$\geq 3.1$ & $28(\mathrm{n}=799)$ & 13.6 & 15.1 & \\
\hline
\end{tabular}

${ }^{a, b}$ Values with different superscript letters within a row differ significantly at $P<0.05$.

${ }^{1}$ Lactating dairy cows $(\mathrm{n}=2,852)$ were screened for PVD at $26 \pm 3$ DIM (exam 1) using the gloved hand technique. Vaginal discharge was scored using a 0 -to-3 scale $[0=$ normal uterine discharge, $1=$ flakes of purulent exudates in the uterine discharge, $2=>50 \%$ of the uterine discharge is made up of purulent exudates, $3=$ hemorrhagic uterine discharge mixed with purulent exudates (adapted from Williams et al., 2005; Sheldon et al., 2006)].

${ }^{2}$ Cows diagnosed with PVD (at exam 1 ) were screened $14 \mathrm{~d}$ posttherapy (at exam 2 ) to determine the response to treatments based on the gloved hand technique (Figure 1). A positive response to treatments (clinical cure) was defined as a cow with PVD at exam 1 ( $26 \pm 3$ DIM) that scored 0 or 1 at exam $2(40 \pm 3$ DIM). CON = untreated control cow; DEX = treated with an intrauterine infusion of a $50 \%$ dextrose solution. 
infusions were performed using individually wrapped, single-use infusion pipettes (Continental Plastic, Delavan, WI). At the beginning of the study, the first treatment (CON or DEX) for each parity group was randomly selected by flipping a coin and then by alternating CON or DEX on every other cow using a sequential treatment allocation chart. Two veterinarians from the research team conducted the clinical examinations, and one veterinarian administered the treatment (DEX). Veterinarians responsible for clinical examinations were blinded to allocation groups and the nature of treatments.

Currently, no antimicrobial is approved in the United States for treatment of CE or PVD in dairy cattle. The use of cephapirin (Metricure, Intervet International, Boxmeer, the Netherlands), which is labeled for treatment of $\mathrm{CE}$ in other countries, is not approved in the United States. Administration of prostaglandin (Dubuc et al., 2011a) or intrauterine infusion of ceftiofur hydrochloride (Galvão et al., 2009a) has been reported to be unsuccessful for the treatment of CE. Therefore, intrauterine infusion of DEX was investigated in an extra-label manner to treat lactating dairy cows with PVD in the present study.

Cows with PVD were screened at $14 \mathrm{~d}$ posttherapy (at exam 2) to assess the response to treatments (clinical cure) based on the gloved hand technique (Figure 1). Assuming that administration of DEX would improve the clinical cure of cows with PVD (proportion of cows that scored 0 at exam 2) by 10 percentage points (e.g., from 30 to 40\%) compared with $\mathrm{CON}$, at least 150 cows per group were needed to be able to detect statistical significance with $95 \%$ confidence and $80 \%$ power. Additionally, assuming that the administration of DEX would improve the reproductive performance of cows with PVD (proportion of cows that scored 0 at exam 2) by 6 percentage points (e.g., from 34 to 40\%) compared with CON, at least 400 cows per group were needed to be able to detect statistical significance with $95 \%$ confidence and $80 \%$ power.

\section{Progesterone Radioimmunoassay}

Blood samples $(10 \mathrm{~mL})$ for determination of blood progesterone $(\mathbf{P} 4)$ concentration were collected at 26 \pm 3 DIM and at $40 \pm 3$ DIM by coccygeal venipuncture (BD Vacutainer, Franklin Lakes, NJ) immediately before administration of treatments to determine the cyclicity status of cows (Stevenson et al., 2006). Cows were classified as cycling when the concentration of P4 from either blood sample was $\geq 1 \mathrm{ng} / \mathrm{mL}$ (high P4; high-high, low-high, or high-low; Stevenson et al., 2006). Noncycling cows were identified when serum concentrations of $\mathrm{P} 4$ from both blood samples were $<1 \mathrm{ng} / \mathrm{mL}$ (low P4; low-low; Stevenson et al., 2006). Briefly, blood samples were centrifuged at $2,785 \times g$ for 20 min immediately after collection, and serum samples were stored at $-20^{\circ} \mathrm{C}$ until assayed for $\mathrm{P} 4$. Serum concentrations of progesterone were determined in duplicates using a modified commercially available RIA kit (Coat-a-Count, Diagnostic Products Corporation, Los Angeles, CA) as previously described (Burke et al., 2003). The inter- and intraassay CV were 7.8 and $11.8 \%$, respectively.

\section{Breeding Management}

The reported voluntary waiting period was $45 \mathrm{~d}$. The breeding program was based only on estrus detection (using tail chalk plus visual observation) twice daily, and all animals presenting signs of standing estrous behavior received AI. Cows that did not display estrous behavior or were not pregnant after 5 consecutive AI were turned into the bull pen (Figure 1). Additionally, open cows at the time of pregnancy diagnosis were reenrolled in the estrus detection program as described previously. All bulls were subjected to the breeding soundness examination once per year, and only bulls with a satisfactory score were used. Pregnancy diagnosis (PD) was performed at $40 \pm 3 \mathrm{~d}$ post-AI via transrectal palpation (Figure 1). Lactating cows confirmed to be pregnant at PD that returned to estrus or presented an abortion were considered pregnancy losses for cows with and without PVD (Figure 1).

\section{Statistical Analyses}

Data from individual lactating dairy cows (e.g., lactation number, DIM, milk yield, service number, pregnancy status) were exported from PCDART. Before data analyses, enrolled lactating dairy cows that met the exclusion criteria (cows that were treated but died or were sold before the AI or pregnancy diagnosis and cows that initiated lactation with an abortion) were removed from the analysis.

The distribution of cows with and without PVD with respect to DIM to first service (d), milk yield $(\mathrm{kg})$, and SCC at the closest DHIA test relative to AI as well as rectal temperature $\left({ }^{\circ} \mathrm{C}\right)$ and mean cervix diameter $(\mathrm{cm})$ at exam 1 were analyzed using the MIXED procedure of SAS (SAS Institute, 2011). Additionally, the distribution of cows with and without PVD with respect to BCS at exam 1 was dichotomized $(\leq 2.75$ or $\geq 3)$ and analyzed using GLIMMIX procedure of SAS (SAS Institute, 2011). Least squares means and standard errors of the means $( \pm \mathrm{SEM})$ were reported. 
The response to treatments (clinical cure) and cycling status (presence of ovarian structures and P4) 14 d posttherapy were assessed for cows with and without PVD. A positive response to treatments (clinical cure) was defined as a cow with PVD at exam $1(26 \pm 3$ DIM) that subsequently scored 0 or 1 at exam 2 (40 \pm 3 DIM). Additionally, the proportions of cows that conceived to first service (PAI) and the proportions of pregnancy losses for the 2 treatment groups (CON or DEX) and for cows without PVD were assessed. Data were arranged in a randomized block design. Data pertaining to response to treatments (clinical cure at exam 2 ), cycling status, presence of ovarian structures (yes or no), the proportion of pregnancy losses, and PAI were analyzed using generalized linear mixed models (Proc GLIMMIX; SAS, 2011). A model procedure that included treatment (CON or DEX), parity (primiparous or multiparous), season (winter, spring, summer, and fall), uterine health status, BCS at calving, milk yield and DIM at the time of AI, sire, and SCC at the closest DHIA test relative to AI was used to compare differences among groups of cows. Nonsignificant variables were eliminated from the logistic model one at a time using the Wald statistic backward selection criterion $(P$ $>0.15)$. Herd was included as a random effect. The estimates (response to treatment, cycling status, PAI, and pregnancy losses) from the final model were reported as least squares means (Bas et al., 2011). Standard errors of the means for the binomial outcomes were computed as described by SAS and reported elsewhere (Brick et al., 2012). The differences between least squares means were computed by including the PDIFF option in the LSMEANS statement (Bas et al., 2011). Differences in individual least squares means were adjusted by using the Tukey-Kramer method.

A Cox proportional hazard model was used to assess the effect of DEX, CON, or cows without PVD on the time to pregnancy up to 300 DIM using the PHREG procedure of SAS (SAS Institute, 2011), controlling for the effects of parity, BCS at calving, uterine health status, and season, if significant. Herds were included in the STRATA statement to account for the herd effects (Dubuc et al., 2011a). Data obtained from SAS output were plotted in Microsoft Excel (Microsoft Corp., Redmond, WA) to graphically depict the proportion of cows pregnant over time (Figure 2). A $P<0.05$ was considered statistically significant and a $P \leq 0.10$ was considered a tendency to differ.

\section{RESULTS}

Initially, 3,181 lactating dairy cows were screened for $\mathrm{CE}$ at $26 \pm 3$ DIM, and data from 329 cows were not available because they died $(\mathrm{n}=26)$, were sold $(\mathrm{n}=$ $292)$, or lost from unknown causes $(n=11)$ before the first AI. Therefore, 2,852 lactating dairy cows $(1,441$ primiparous and 1411 multiparous) were available for the final analyses (Tables 1, 2, 3, and 4).

\section{Diagnosis of CE and Response to Treatments}

The prevalence of PVD at exam 1 (26 \pm 3 DIM $)$ was $33.4 \%$ (scores 2 and 3 combined; Table 1). The distribution of lactating dairy cows with and without PVD with respect to herd, parity, season, and P4 status at enrollment is presented in Table 2. The response to treatments was assessed $14 \mathrm{~d}$ posttherapy at exam $2(40$ \pm 3 DIM; Table 1) for cows with PVD. A greater proportion of cows treated with DEX (59.7\%) were cured compared with CON cows $(51.1 \%, P=0.04$; Table 1$)$. Additionally, we found no significant differences $(P=$ $0.9)$ in the proportion of cows that died within $14 \mathrm{~d}$ post-treatment between CON (2\%) and DEX (1.5\%).

Cervical diameter was estimated via transrectal ultrasonography at the time of exam 1 (26 \pm 3 DIM) and exam $2(40 \pm 3$ DIM; Table 1$)$. Cows without PVD had smaller cervical diameters compared with cows diagnosed with PVD $(P<0.0001$; Table 3$)$. The distribution of cows with and without PVD with respect to DIM to first service, milk yield, BCS at exam 1, rectal body temperature, mean cervix diameters at exam 1, and SCC at the closest DHIA test relative to AI were compared among groups and are presented in Table 3. We detected no significant differences between DEX and CON cows for the parameters assessed; however, DIM to first service, BCS, and mean cervix diameters did differ between cows with and without PVD (Table $3)$.

\section{Ovarian Structures, Cycling Status, and Effect of Treatments on PAI}

Parity, uterine health status, and BCS at calving were significantly associated $(P<0.05)$ with PAI and remained in the final model. The proportions of ovarian structures (presence of CL, follicles, or cysts) at exam 1 (26 \pm 3 DIM) and at exam $2(40 \pm 3$ DIM $)$ as well as the proportion of cows cycling (serum concentrations of $\mathrm{P} 4 \geq 1 \mathrm{ng} / \mathrm{mL})$ were not different $(P>$ 0.05 ) between DEX and CON cows (Table 4). However, lactating cows without PVD had a greater $(P>0.05)$ proportion of CL and follicles with lower proportion of cysts at exam 1 and more cycling cows compared with cows with PVD (Table 4). Uterine heath status (with vs. without PVD) had a detrimental effect $(P<0.05$; Table 4) on first-service PAI, pregnancy loss, and time 
Table 2. Distribution of lactating dairy cows with purulent vaginal discharge (PVD) with respect to herd, parity, season, and progesterone (P4) status at the time of enrollment

\begin{tabular}{lcc}
\hline & \multicolumn{2}{c}{ Cows with $\mathrm{PVD}^{1}$} \\
\cline { 2 - 3 } & $\begin{array}{c}\text { CON } \\
(\mathrm{n}=491)\end{array}$ & $\begin{array}{c}\text { DEX } \\
(\mathrm{n}=456)\end{array}$ \\
Variable & & \\
Herd (no.) & 295 & 273 \\
A & 196 & 183 \\
B & & \\
Parity (no.) & 290 & 275 \\
1 & 201 & 181 \\
$\geq 2$ & & \\
Season (no.) & 111 & 98 \\
Winter & 184 & 167 \\
Spring & 151 & 149 \\
Summer & 45 & 42 \\
Fall & 22.9 & 22 \\
P4 ( $\geq 1 \mathrm{ng} / \mathrm{mL})$ at $26 \pm 3$ DIM (\%) & & \\
\hline
\end{tabular}

${ }^{1}$ Lactating dairy cows $(\mathrm{n}=2,852)$ were screened for PVD at $26 \pm 3$ DIM using the gloved hand technique. Cows with PVD were randomly assigned to 1 of 2 treatment groups: (1) intrauterine infusion $(\sim 200$ $\mathrm{mL}$ ) of a $50 \%$ dextrose solution (DEX: $\mathrm{n}=456)$, or $(2)$ untreated control cows $(\mathrm{CON} ; \mathrm{n}=491)$. to pregnancy up to 300 DIM (Figure 2). The proportion of PAI for first service was greater $(P=0.01)$ in DEX $(29.8 \pm 2 \%)$ compared with CON cows $(22.7 \pm 2 \%)$, whereas overall PAI in cows without PVD was greater $(37.0 \pm 1 \%$; Table 4$)$ than that in DEX or CON cows $(P<0.0001)$. The presence of PVD (CON and DEX) was significantly associated with increased pregnancy losses compared with cows without PVD (Table 4; $P$ $=0.03)$.

\section{DISCUSSION}

The objectives of this study were to assess the responses to treatment (clinical cure and cow cyclicity 14 d posttherapy) of cows with PVD that received intrauterine infusion of a hypertonic solution of $50 \%$ DEX and the subsequent PAI in cows with PVD compared with cows without PVD. The study showed that (1) cows with PVD had greater mean cervix diameters,

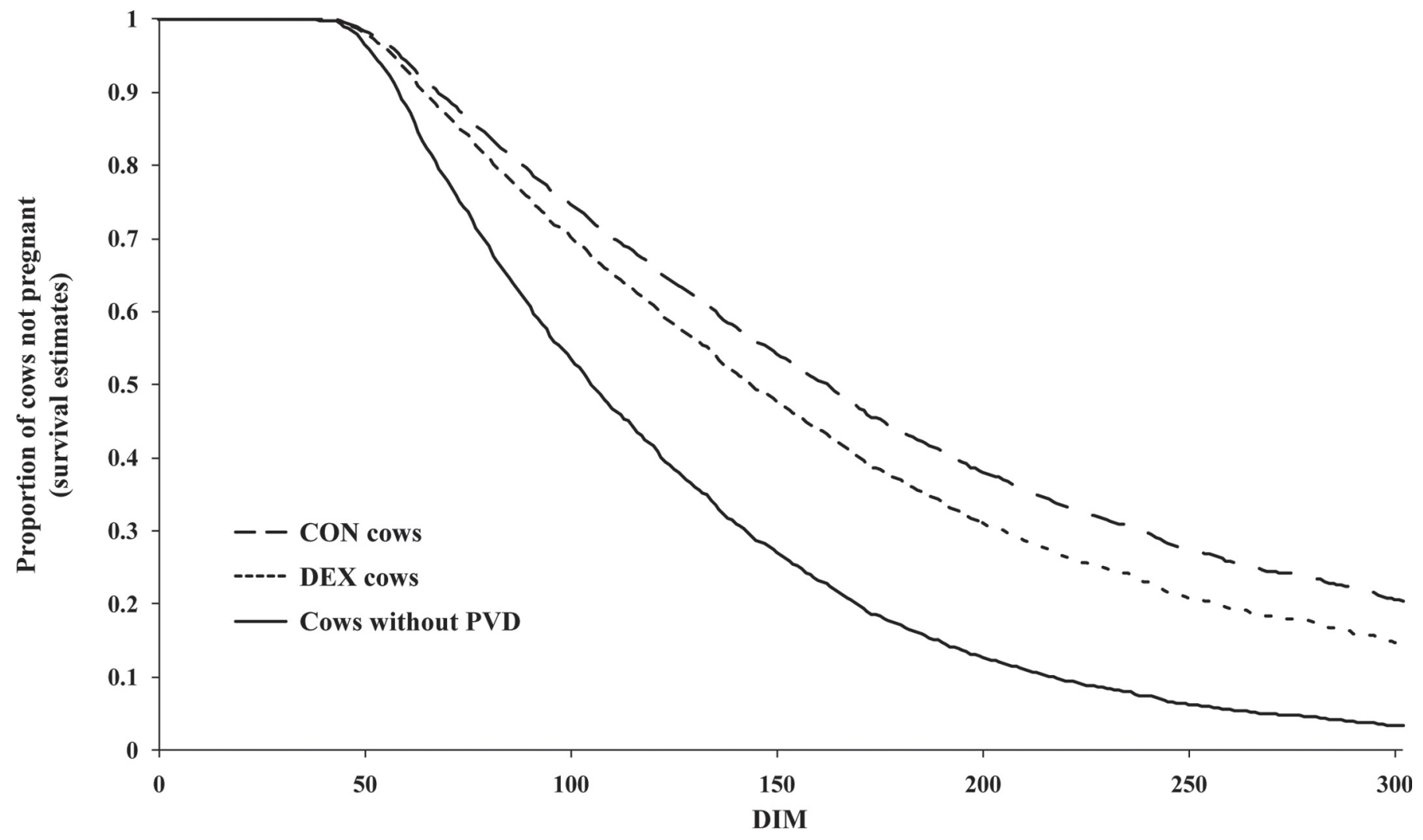

Figure 2. Survival curves for time to pregnancy after the voluntary waiting period of dairy cows with or without purulent vaginal discharge (PVD). Lactating dairy cows $(\mathrm{n}=2,852)$ were screened for PVD at $26 \pm 3$ DIM using the gloved hand technique and measurement of cervical diameter and randomly assigned into 1 of 2 groups: (1) intrauterine infusion ( $200 \mathrm{~mL})$ of a $50 \%$ dextrose solution (DEX; $\mathrm{n}=456)$, or (2) untreated control cows $(\mathrm{CON} ; \mathrm{n}=491)$. Cows without PVD $(\mathrm{n}=1,905)$ were included in the survival function estimates. Adjusted hazard ratios $(\mathrm{AHR} ; 95 \% \mathrm{CI})$ for pregnancy $(P<0.05)$ were $0.44(0.42-0.49)$ and $0.51(0.50-0.63)$ for CON and DEX, respectively $($ referent $=$ cows without PVD). Median time to pregnancy (95\% CI) was 123 d (119-126), 162 d (154-171), and 183 d (173-192) for cows without PVD, DEX, and CON, respectively. 
Table 3. Distribution (LSM \pm SEM) of lactating dairy cows with and without purulent vaginal discharge $(\mathrm{PVD})^{1}$

\begin{tabular}{|c|c|c|c|c|}
\hline \multirow[b]{2}{*}{ Variable $^{2}$} & \multicolumn{2}{|c|}{ Cows with PVD } & \multirow{2}{*}{$\begin{array}{c}\text { Cows } \\
\text { without PVD } \\
(\mathrm{n}=1,905)\end{array}$} & \multirow[b]{2}{*}{$P$-value } \\
\hline & $\begin{array}{c}\mathrm{CON} \\
(\mathrm{n}=491)\end{array}$ & $\begin{array}{c}\text { DEX } \\
(\mathrm{n}=456)\end{array}$ & & \\
\hline DIM at first service (d) & $83.7 \pm 1.4^{\mathrm{a}}$ & $83.7 \pm 1.5^{\mathrm{a}}$ & $70.8 \pm 0.9^{\mathrm{b}}$ & $<0.0001$ \\
\hline Milk yield (kg) & $33.1 \pm 0.43$ & $33.2 \pm 0.45$ & $32.73 \pm 0.45$ & 0.15 \\
\hline \multicolumn{5}{|l|}{$\operatorname{BCS}(\%)$} \\
\hline$\leq 2.75$ & $76.0 \pm 2.4^{\mathrm{a}}$ & $74.9 \pm 2.5^{\mathrm{a}}$ & $58.3 \pm 1.3^{\mathrm{b}}$ & $<0.0001$ \\
\hline$\geq 3.0$ & $24.0 \pm 2.4^{\mathrm{b}}$ & $25.1 \pm 2.5^{\mathrm{b}}$ & $41.7 \pm 1.3^{\mathrm{a}}$ & $<0.0001$ \\
\hline 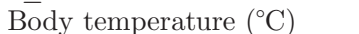 & $38.8 \pm 0.1$ & $38.8 \pm 0.1$ & $38.7 \pm 0.05$ & 0.10 \\
\hline Mean cervix diameter $(\mathrm{cm})$ & $3.2 \pm 0.2^{\mathrm{a}}$ & $3.3 \pm 0.2^{\mathrm{a}}$ & $2.9 \pm 0.1^{\mathrm{b}}$ & $<0.0001$ \\
\hline $\mathrm{SCC}\left(\times 10^{3}\right)$ & $185 \pm 41$ & $170 \pm 43$ & $128 \pm 32$ & 0.52 \\
\hline
\end{tabular}

$\overline{\mathrm{a}, \mathrm{b}}$ Values with different superscript letters within a row differ significantly at $P<0.05$.

${ }^{1}$ Lactating dairy cows $(\mathrm{n}=2,852)$ were screened for PVD at $26 \pm 3$ DIM using gloved hand technique. Cows with PVD were randomly assigned to 1 of 2 treatment groups: intrauterine infusion $(\sim 200 \mathrm{~mL})$ of a $50 \%$ dextrose solution (DEX; $\mathrm{n}=456$ ) or untreated control cows $(\mathrm{CON} ; \mathrm{n}=491)$. Information from cows without PVD $(\mathrm{n}=1,905)$ was included in the analysis.

${ }^{2}$ Milk yield and SCC were recorded at closest DHIA relative to first service; body temperature, BCS, and mean cervix diameter were recorded at $26 \pm 3$ DIM.

Table 4. Proportion (\%) of ovarian structures [presence of follicles, corpora lutea (CL), or cysts] and cycling status based on serum concentrations of progesterone $(\mathrm{P} 4)$ in lactating dairy cows diagnosed with purulent vaginal discharge (PVD) ${ }^{1}$

\begin{tabular}{|c|c|c|c|c|}
\hline Variable & \multicolumn{2}{|c|}{ Cows with PVD } & $\begin{array}{c}\text { Cows } \\
\text { without PVD } \\
(\mathrm{n}=1,905)\end{array}$ & $P$-value \\
\hline Follicles $(\%)$ & $95.4 \pm 0.7^{\mathrm{b}}$ & $95.5 \pm 0.7^{\mathrm{b}}$ & $98.2 \pm 0.3^{\mathrm{a}}$ & 0.0009 \\
\hline $\mathrm{CL}(\%)$ & $41.2 \pm 2.5^{\mathrm{b}}$ & $39.5 \pm 2.5^{\mathrm{b}}$ & $47.5 \pm 1.6^{\mathrm{a}}$ & 0.0021 \\
\hline $\begin{array}{l}\text { Follicles (\%) } \\
\text { CL }(\%)\end{array}$ & $97.2 \pm 0.7$ & $98.6 \pm 0.7$ & $\mathrm{NA}^{5}$ & 0.44 \\
\hline $\begin{array}{l}\text { CL (\%) } \\
\text { Cysts (\%) }\end{array}$ & $\begin{array}{r}53.5 \pm 2.8 \\
7.5 \pm 1.3\end{array}$ & $\begin{aligned} 59.1 & \pm 2.8 \\
6.2 & \pm 1.3\end{aligned}$ & $\begin{array}{l}\text { NA } \\
\text { NA }\end{array}$ & $\begin{array}{l}0.24 \\
0.70\end{array}$ \\
\hline First-service PAI for cows with PVD only ${ }^{6}(\%)$ & $22.7 \pm 2^{\mathrm{b}}$ & $29.8 \pm 2^{\mathrm{a}}$ & - & 0.01 \\
\hline First-service PAI for all cows ${ }^{7}(\%)$ & $22.5 \pm 2^{\mathrm{c}}$ & $29.2 \pm 2^{\mathrm{b}}$ & $37.0 \pm 1^{\mathrm{a}}$ & $<0.0001$ \\
\hline Pregnancy $\operatorname{loss}^{8}(\%)$ & $8.9 \pm 1^{\mathrm{a}}$ & $8.4 \pm 1^{\mathrm{a}}$ & $5.6 \pm 0.5^{\mathrm{b}}$ & 0.03 \\
\hline
\end{tabular}

${ }^{1}$ Lactating dairy cows $(\mathrm{n}=2,852)$ were screened for PVD at $26 \pm 3$ DIM using gloved hand technique. Cows with PVD were randomly assigned to 1 of 2 treatment groups: intrauterine infusion $(\sim 200 \mathrm{~mL})$ of a $50 \%$ dextrose solution $(\mathrm{DEX} ; \mathrm{n}=456)$ or untreated control cows $(\mathrm{CON} ; \mathrm{n}=$ 491). Information from cows without PVD $(\mathrm{n}=1,905)$ was included in the analysis.

${ }^{2}$ The proportions (\%; LSM $\pm \mathrm{SEM}$ ) of cycling lactating dairy cows based on serum concentrations of P4 were reported. Blood samples were collected from cows diagnosed with and without PVD at exam 1 (26 \pm 3 DIM) and exam 2 (at $40 \pm 3$ DIM). Cows were classified as cycling when concentrations of $\mathrm{P} 4$ from 1 of 2 blood samples were $\geq 1 \mathrm{ng} / \mathrm{mL}$ [high P4; high-high $(\mathrm{CON}=15 \%$ and $\mathrm{DEX}=14 \%)$, low-high $(\mathrm{CON}=$ $20 \%$ and $\mathrm{DEX}=32.6)$, or high-low $(\mathrm{CON}=7.9 \%$ and $\mathrm{DEX}=8 \%)$. Cows were classified as noncycling when serum concentrations of $\mathrm{P} 4$ from both blood samples were $<1 \mathrm{ng} / \mathrm{mL}$ (low P4; low-low, CON $=57.1 \%$ and $\mathrm{DEX}=46.2 \%$ ).

${ }^{3}$ The proportion (\%; LSM \pm SEM) of ovarian structures (presence or absence of follicles, CL, or cysts) was recorded at $26 \pm 3$ DIM in lactating dairy cows with and without PVD.

${ }^{4}$ The proportion (\%; LSM \pm SEM) of ovarian structures (presence or absence of follicles, CL, or cysts) was recorded at $40 \pm 3$ DIM in lactating dairy cows with PVD.

${ }^{5} \mathrm{NA}=$ not assessed.

${ }^{6}$ Proportions (\%; LSM \pm SEM) of first-service pregnancies per AI (PAI) in cows with PVD.

${ }^{7}$ Proportions $(\% ; \mathrm{LSM} \pm \mathrm{SEM})$ of first-service PAI in cows with and without PVD $(\mathrm{n}=1,903)$.

${ }^{8}$ The proportion of pregnancy losses between the pregnancy diagnosis $(40 \pm 3 \mathrm{~d}$ post-AI) and parturition (e.g., pregnant cows that returned to estrus, abortion) for cows with and without PVD. 
lower proportion of CL and follicles, and a higher prevalence of cysts compared with cows without PVD at exam 1; (2) treatment with DEX increased the proportion of cows that were cured, had improved cyclicity $14 \mathrm{~d}$ posttherapy, and had greater PAI compared with CON cows; (3) pregnancy losses were higher for PVD cows (DEX and CON) compared with cows without PVD; and (4) cows without PVD had a lower proportion of cysts at exam 1 with greater cyclicity and PAI compared with DEX or CON cows.

The prevalence of PVD at exam 1 was $33.4 \%$, within the range of values cited in the literature for cows under conventional management (LeBlanc et al., 2002a; Gilbert et al., 2005; Williams et al., 2005; Brick et al., 2012). Postpartum CE has been defined as the presence of mucopurulent or purulent vaginal discharge using vaginoscopy at 26 DIM with a cervix diameter $\geq 7.5 \mathrm{~cm}$ (measured by transrectal palpation) and without systemic signs of illness (e.g., fever; LeBlanc et al., 2002a; Kasimanickam et al., 2005). In the present study, cows with PVD were diagnosed according to the vaginal discharge using the gloved hand technique. Cervix diameters for cows with and without PVD were measured by transrectal ultrasound as reported elsewhere (Brick et al., 2012). Although cows with PVD had similar mean cervix diameters, the mean diameter was greater for PVD cows $(>3.2 \mathrm{~cm})$ compared with cows without PVD $(2.9 \mathrm{~cm})$. Additionally, increased mean cervix diameters were associated with reduced first-service PAI in cows diagnosed with PVD compared with cows without PVD. Previous studies reported that CE cows present a cervical diameter of $\geq 7.5 \mathrm{~cm}$ at 20 DIM (based on transrectal palpation; LeBlanc et al., 2002a; Sheldon et al., 2006, 2009). The assessment of cervical diameter as a means to diagnose CE or PVD in cows may vary considerably according to the method used (e.g., transrectal ultrasonography vs. transrectal palpation). The use of different methods of measurement may explain, at least in part, the values for cervical diameter reported in the present study compared with those values reported via transrectal palpation (LeBlanc et al., 2002a; Dubuc et al., 2011a). Furthermore, rectal temperature at the time of treatment $(26 \pm 3$ DIM) was not different between cows with and without PVD in this study and as reported elsewhere (LeBlanc et al., 2002b; Brick et al., 2012). The response to treatments (clinical cure and cow cyclicity) and survival were assessed $14 \mathrm{~d}$ posttherapy. The proportions of cows with a vaginal discharge score of 0 or 1 (clinical cure) and cyclicity were significantly higher in DEX cows compared with CON cows. Previous studies reported spontaneous cure rates of 59\% (Gautam et al., 2009), 63\% (Dubuc et al., 2011a), and 77\% (LeBlanc et al., 2002b) for dairy cows diagnosed with endometritis. In the present study, the proportions of cows with PVD that were cured was $51.1 \%$ for CON (untreated cows) and $59.7 \%$ for DEX cows. Perhaps the timing or technique used for diagnosis (LeBlanc et al., 2002b; Dubuc et al., 2011a) with the administration of antibiotics (before, at the time of, or after diagnosis) or $\mathrm{PGF}_{2 \alpha}$ (as part of the reproductive program; Dubuc et al., 2011a) explains, at least in part, the differences observed among studies. It is important to note that none of the cows (with or without PVD) enrolled in the present study was administered $\mathrm{PGF}_{2 \alpha}$ or antibiotics. Vaginal discharges from cows (and cervical diameter) are expected to decrease over time as the inflammation associated with CE or PVD resolves following treatment administration (Runciman et al., 2008). According to the current study, cows with PVD benefited (clinical cure and cyclicity) from the administration of DEX at exam 1.

The presence or absence of ovarian structures (follicles, CL, and cysts) and cyclicity status were assessed via transrectal ultrasonography and by concentration of serum P4 at exam 1 and exam 2 in cows with and without PVD, respectively. In lactating cows without PVD, the presence or absence of ovarian structures (follicles, CL, and cysts) was assessed via transrectal ultrasonography at exam 1 and cyclicity status was assessed via concentrations of serum $\mathrm{P} 4$ at exam 1 and exam 2. It is important to note the difference observed between the proportion of cows with a CL and $\mathrm{P} 4$ concentration $(\geq 1 \mathrm{ng} / \mathrm{mL})$ at exam 1 (26 \pm 3 DIM). In lactating dairy cows, the first dominant follicle ovulates at $16.1 \pm 3.5 \mathrm{~d}$ postpartum (Beam and Butler, 1998). Therefore, it is possible that sampling cows and screening the ovary for a CL at $26 \pm 3$ DIM could misclassify those cows at 3 to $5 \mathrm{~d}$ after ovulation. Furthermore, in the present study, we did not assess CL diameters, and perhaps the size of the CL explains the differences observed between the proportion of cows with a CL and concentrations of P4 at exam 1. Although the proportion of ovarian structures did not differ between CON and DEX cows, cycling status was greater for DEX cows compared with CON cows. Furthermore, lactating cows without PVD had a greater cyclicity (including CL and follicles at exam 1) with a lower prevalence of cysts compared with PVD cows. It has been shown that contamination of the uterus with recognized pathogens is associated with ovarian dysfunction (perturbed follicular growth, smaller CL diameter with reduced plasma progesterone concentration) in postpartum dairy cows (Williams et al., 2007). Furthermore, cows diagnosed with $\mathrm{CE}$ have a significantly greater risk of developing cysts (López-Gatius et al., 2002; Brick et al., 2012), with subsequent reduced 
fertility, compared with cows without CE (Brick et al., 2012).

We assessed the proportion of cows that died, the clinical response to treatments (clinical cure) $14 \mathrm{~d}$ posttherapy, PAI following the administration of DEX to PVD cows, and the proportions of pregnancy losses. In the present study, cows treated with DEX at exam 1 had improved clinical cure and increased serum progesterone concentrations and PAI (for first service and overall) compared with CON cows. When cows with and without PVD were considered in the analysis, reproductive performance (first-service PAI and maintenance of pregnancy) was greater for cows without PVD. Moreover, the DEX cows had a 7-percentagepoint greater first-service PAI without significant differences in pregnancy losses compared with untreated CON cows. Uterine health disorders (Dubuc et al., 2011b; Brick et al., 2012) and anovular lactating dairy cows (Bisinotto et al., 2010) are associated with decreased first-service PAI and increased pregnancy losses (Brick et al., 2012). Interestingly, pregnancy losses were almost 2-fold higher in cows with CE compared with cows without $\mathrm{CE}$ in the present study and as reported previously (Brick et al., 2012).

The administration of intrauterine ceftiofur hydrochloride (Galvão et al., 2009a) or crystalline free acid (Brick et al., 2012) for cows with CE has been shown unsuccessful at improving PAI when administered in conjunction with prostaglandin. Furthermore, administration of prostaglandin alone for cows diagnosed with PVD has been reported to have no effect (Dubuc et al., 2011a) on PAI in lactating dairy cows. In our study, the administration of DEX alone improved the proportion of cows with clinical cure and cyclicity at exam 2 and improved subsequent reproductive performance compared with untreated CON cows. In the present study, all cows were subjected to the same reproductive program (visual observation of estrous for the first 5 $\mathrm{AI}$ and then turned with bulls), and reproductive performance of DEX cows was greater than that of CON cows. Our previous study showed that administration of DEX improved clinical cure of PVD cows compared with untreated CON cows (Brick et al., 2012).

The use of intrauterine DEX in cows with PVD compared with CON cows may favor faster uterine recovery by inhibiting local bacterial growth, increasing uterine tone, or by nurturing endometrial cells. Previous studies have shown the ability of sugar (hypertonic sucrose solution) to aid in wound healing through inhibition of bacterial growth such as E. coli (Chirife et al., 1983; Archer et al., 1990; Sharon, 2006). Sucrose has also been shown to control bacterial infections by causing an osmotic draw of fluid out of the affected area and reducing the water activity (Chirife et al., 1983), which is required for bacteria to survive. Decreasing the bacterial production of proteolytic enzymes (leading to less tissue damage), limiting absorption of bacterial toxins, source of energy for damaged tissues, and reducing the water activity required for bacteria to survive were the principles behind the use of hypertonic solutions (glucose or sucrose) for treatment of acute peritonitis in rabbits (Narat, 1923), human wounds (Chirife et al., 1983), and equine wounds (White, 1995). The osmotic draw of fluid out of the tissues would aid in tissue contraction (Kilic, 2001), thereby causing increased uterine tone. Furthermore, an in vitro study has shown that mannose (a sugar monomer) inhibits the adhesion of Pseudomonas aeruginosa and E. coli to endometrial epithelial cells from equine endometrium (King et al., 2000). It is proposed that the intrauterine infusion of a hypertonic solution such as 50\% DEX may reduce the growth rate of bacteria in the uterus (by lowering the water activity as suggested by Chirife et al., 1983), increase uterine tone, and provide energy to the natural uterine defenses (e.g., macrophages, neutrophils) to control the infection and improve the overall reproductive performance (clinical cure and PAI) as observed for DEX cows. Another likely explanation is that intrauterine infusion of DEX (200 mL) could have flushed the uterus and, with the likely reflux into the vaginal canal, controlled the infection. In future studies, the use of a placebo (e.g., distilled water) would allow us to assess whether the benefits observed in the present study were due to the DEX, the flushing effect, or to a combination of both. The use of intrauterine infusion of DEX for the treatment of PVD in lactating dairy cows provided useful information for the development of new hypotheses for future studies to elucidate the underlying mechanisms by which infection is controlled and its association with clinical recovery and reproductive performance.

\section{CONCLUSIONS}

The development of effective alternative therapies to antibiotics for the treatment of uterine diseases such as $\mathrm{CE}$ and puerperal metritis is needed due to the emergence of multidrug resistant bacteria in lactating dairy cows. Under the field conditions described here (certified organic management), this randomized clinical study showed that administration of DEX alone improved clinical cure, resumption of postpartum estrous cycle, and the subsequent reproductive performance of PVD cows compared with untreated CON cows. It is important to note that lactating dairy cows can achieve acceptable performance (conception rate and 
milk yield) without using reproductive hormones, as shown for those cows that did not develop uterine infections. The economic benefits of dairy cows under certified organic management require further analyses by considering the performance of lactating cows (health, reproduction, and milk yield), milk and feed prices, and replacement costs.

\section{ACKNOWLEDGMENTS}

The authors thank the collaborating dairy farm and their staff for providing the animals used in this study and their assistance during the project. This project was partially supported by the USDA-Animal Health Formula Fund (Washington, DC) and Aurora Organic Farms (Boulder, CO). The constructive comments and suggestions of anonymous reviewers are greatly appreciated.

\section{REFERENCES}

Archer, H. G., S. Barnett, S. Irving, K. R. Middleton, and D. V. Seal. 1990. A controlled model of moist wound healing: Comparison between semi-permeable film, antiseptics and sugar paste. J. Exp. Pathol. (Oxford) 71:155-170.

Bas, S., A. Hoet, P. Rajala-Schultz, D. Sanders, and G. M. Schuenemann. 2011. The use of plastic cover sheaths at the time of artificial insemination improved fertility of lactating dairy cows. J. Dairy Sci. 94:793-799.

Beam, S. W., and W. R. Butler. 1998. Energy balance, metabolic hormones, and early postpartum follicular development in dairy cows fed prilled lipid. J. Dairy Sci. 81:121-131.

Bisinotto, R. S., E. S. Ribeiro, L. T. Martins, R. S. Marsola, L. F. Greco, M. G. Favoreto, C. A. Risco, W. W. Thatcher, and J. E. P. Santos. 2010. Effect of interval between induction of ovulation and artificial insemination (AI) and supplemental progesterone for resynchronization on fertility of dairy cows subjected to a 5 -d timed AI program. J. Dairy Sci. 93:5798-5808.

Brick, T. A., G. M. Schuenemann, S. Bas, J. B. Daniels, C. R. Pinto, D. M. Rings, and P. J. Rajala-Schultz. 2012. Effect of intrauterine dextrose or antibiotic therapy on reproductive performance of lactating dairy cows diagnosed with clinical endometritis. J. Dairy Sci. 95:1894-1905.

Burke, C. R., M. L. Mussard, C. L. Gasser, D. E. Grum, and M. L. Day. 2003. Estradiol benzoate delays new follicular wave emergence in a dose-dependent manner after ablation of the dominant ovarian follicle in cattle. Theriogenology 60:647-658.

Chirife, J., L. Herszage, A. Joseph, and E. S. Kohn. 1983. In vitro study of bacterial growth inhibition in concentrated sugar solutions: Microbiological basis for the use of sugar in treating infected wounds. Antimicrob. Agents Chemother. 23:766-773.

Drillich, M., O. Beetz, A. Pfützner, M. Sabin, H. J. Sabin, P. Kutzer, H. Nattermann, and W. Heuwieser. 2001. Evaluation of a systemic antibiotic treatment of toxic puerperal metritis in dairy cows. J. Dairy Sci. 84:2010-2017.

Dubuc, J., T. F. Duffield, K. E. Leslie, J. S. Walton, and S. J. LeBlanc. 2011a. Randomized clinical trial of antibiotic and prostaglandin treatments for uterine health and reproductive performance in dairy cows. J. Dairy Sci. 94:1325-1338.

Dubuc, J., T. F. Duffield, K. E. Leslie, J. S. Walton, and S. J. LeBlanc. 2011b. Effects of postpartum uterine diseases on milk production and culling in dairy cows. J. Dairy Sci. 94:1339-1346.
Ferguson, J. D., D. T. Galligan, and N. Thomsen. 1994. Principal descriptors of body condition score in Holstein cows. J. Dairy Sci. 77:2695-2703.

Földi, J., M. Kulcsar, A. Pecsi, B. Huyghe, C. de Sa, J. A. Lohuis, P. Cox, and G. Huszenicza. 2006. Bacterial complications of postpartum uterine involution in cattle. Anim. Reprod. Sci. 96:265-281.

Galvão, K. N., L. F. Greco, J. M. Vilela, M. F. Sá Filho, and J. E. Santos. 2009a. Effect of intrauterine infusion of ceftiofur on uterine health and fertility in dairy cows. J. Dairy Sci. 92:1532-1542.

Gautam, G., T. Nakao, M. Yusuf, and K. Koike. 2009. Prevalence of endometritis during the postpartum period and its impact on subsequent reproductive performance in two Japanese dairy herds. Anim. Reprod. Sci. 116:175-187.

Gilbert, R. O., S. T. Shin, C. L. Guard, H. N. Erb, and M. Frajblat. 2005. Prevalence of endometritis and its effects on reproductive performance of dairy cows. Theriogenology 64:1879-1888.

Heuwieser, W., B. A. Tenhagen, M. Tischer, J. Lühr, and H. Blum. 2000. Effect of three programs for the treatment of endometritis on the reproductive performance of a dairy herd. Vet. Rec. 146:338-341.

Kasimanickam, R., T. F. Duffield, R. A. Foster, C. J. Gartley, K. E. Leslie, J. S. Walton, and W. H. Johnson. 2005. A comparison of the cytobrush and uterine lavage techniques to evaluate endometrial cytology in clinically normal postpartum dairy cows. Can. Vet. J. 46:255-259.

Kasimanickam, R., M. Overton, D. A. Moore, and W. M. Sischo. 2010. Effects of Excenel RTU ${ }^{\circledR}$ and Polyflex ${ }^{\circledR}$ on cure and reproductive performance of dairy cows diagnosed with acute puerperal metritis. Clin. Theriogenol. 2:388. (Abstr.)

Kilic, A. 2001. Healing of diabetic ulcers with granulated sugar. Plast. Reconstr. Surg. 108:585.

King, S. S., D. A. Young, L. G. Nequin, and E. M. Carnevale. 2000 Use of specific sugars to inhibit bacterial adherence to equine endometrium in vitro. Am. J. Vet. Res. 61:446-449.

LeBlanc, S. J. 2008. Postpartum uterine disease and dairy herd reproductive performance: A review. Vet. J. 176:102-114.

LeBlanc, S. J., T. F. Duffield, K. E. Leslie, K. G. Bateman, G. P. Keefe, J. S. Walton, and W. H. Johnson. 2002a. Defining and diagnosing postpartum clinical endometritis and its impact on reproductive performance in dairy cows. J. Dairy Sci. 85:2223-2236.

LeBlanc, S. J., T. F. Duffield, K. E. Leslie, K. G. Bateman, G. P. Keefe, J. S. Walton, and W. H. Johnson. 2002b. The effect of treatment of clinical endometritis on reproductive performance in dairy cows. J. Dairy Sci. 85:2237-2249.

López-Gatius, F., P. Santolaria, J. Yániz, M. Fenech, and M. LópezBéjar. 2002. Risk factors for postpartum ovarian cysts and their spontaneous recovery or persistence in lactating dairy cows. Theriogenology 58:1623-1632.

McDougall, S. 2001. Effect of intrauterine antibiotic treatment on reproductive performance of dairy cows following periparturient disease. N. Z. Vet. J. 49:150-158.

McLaughlin, C., C. LaGrow, C. Daugherty, E. Stanisiewski, and M. Lucas. 2010. Control of acute postpartum metritis in lactating dairy cows at high risk of developing metritis following dystocia, stillbirth, twinning and/or retained placenta/fetal membranes with ceftiofur crystalline free acid sterile suspension (CCFA-SS). J. Dairy Sci. 93(E-Suppl. 1):407. (Abstr.)

Narat, J. K. 1923. Experimental study upon the use of intra-abdominal injections of hypertonic glucose solution in the treatment of peritonitis. Ann. Surg. 78:357-363.

NRC. 2001. Nutrient Requirements of Dairy Cattle. 7th rev. ed. National Academy Press, Washington, DC.

Overton, M., and J. Fetrow. 2008. Economics of postpartum uterine health. Pages 39-43 in Proc. Dairy Cattle Reprod. Counc. Conv., Omaha, NE. Dairy Cattle Reproductive Council, Hartland, WI.

Runciman, D. J., G. A. Anderson, J. Malmo, and G. M. Davis. 2008. Use of postpartum vaginoscopic (visual vaginal) examination of dairy cows for the diagnosis of endometritis and the association of endometritis with reduced reproductive performance. Aust. Vet. J. $86: 205-213$. 
Santos, T. M. A., L. S. Caixeta, V. S. Machado, A. K. Rauf, R. O Gilbert, and R. C. Bicalho. 2010. Antimicrobial resistance and presence of virulence factor genes in Arcanobacterium pyogenes isolated from the uterus of postpartum dairy cows. Vet. Microbiol. 145:84-89.

SAS Institute. 2011. SAS/STAT 9.2 User's Guide. 2nd ed. SAS Institute Inc., Cary, NC.

Schuenemann, G.M., I. Nieto, S. Bas, K.N. Galvão, and J. Workman. 2011. Dairy calving management: Effect of perineal hygiene scores on metritis. J. Dairy Sci. 94(E-Suppl. 1):744. (Abstr.)

Sharon, N. 2006. Carbohydrates as future anti-adhesion drugs for infectious diseases. Biochim. Biophys. Acta 1760:527-537.

Sheldon, I. M., J. Cronin, L. Goetze, G. Donofrio, and H. J. Schuberth. 2009. Defining postpartum uterine disease and the mechanisms of infection and immunity in the female reproductive tract in cattle. Biol. Reprod. 81:1025-1032.

Sheldon, I. M., G. S. Lewis, S. LeBlanc, and R. O. Gilbert. 2006. Defining postpartum uterine disease in cattle. Theriogenology 65:1516-1530.
Stevenson, J. S., J. R. Pursley, H. A. Garverick, P. M. Fricke, D. J. Kesler, J. S. Ottobre, and M. C. Wiltbank. 2006. Treatment of cycling and noncycling lactating dairy cows with progesterone during Ovsynch. J. Dairy Sci. 89:2567-2578.

Stevenson, J. S., and S. M. Tiffany. 2004. Resychronizing estrus and ovulation after not-pregnant diagnosis and various ovarian states including cysts. J. Dairy Sci. 87:3658-3664.

White, G. W. 1995. Maltodextrin NF powder: A new concept in equine wound healing. J. Equine Vet. Sci. 15:296-298.

Williams, E. J., D. P. Fischer, D. E. Noakes, G. C. W. England, A. Rycroft, H. Dobson, and I. M. Sheldon. 2007. The relationship between uterine pathogen growth density and ovarian function in the postpartum dairy cow. Theriogenology 68:549-559.

Williams, E. J., D. P. Fischer, D. U. Pfeiffer, G. C. W. England, D. E. Noakes, H. Dobson, and I. M. Sheldon. 2005. Clinical evaluation of postpartum vaginal mucus reflects uterine bacterial infection and the immune response in cattle. Theriogenology 63:102-117. 